Check for updates

Cite this: RSC Adv., 2017, 7, 51008

Received 30th August 2017 Accepted 30th October 2017

DOI: 10.1039/c7ra09634h

rsc.li/rsc-advances

\title{
Applications of graphene-based composite hydrogels: a review
}

\begin{abstract}
Hao Lu, ${ }^{a}$ Shengtao Zhang, (D)*a Lei Guo (D) ${ }^{\text {b }}$ and Weihua Lic
Graphene-based hydrogels, which utilize graphene as a filler to blend with various molecules, have fully exploited the addition of graphene and exhibited more prominent performances in energy storage, wastewater treatment, biosensor and technology, and biomedicine compared with traditional hydrogels. Herein, recent progress in graphene-based composite hydrogels has been reviewed and the whole article simply introduces the preparation methods of the different types of hydrogels. Besides, various areas of applications of the graphene-based hydrogels are revealed emphatically such as adsorbents for purification, adsorbents to specific dyestuffs, and biosensors with high energy density etc. Moreover, several urgent issues, which still limit the further developments of the graphene-based hydrogels are expressed in the review as well. Finally, it is achievable to introduce novel functional materials into graphene-based hydrogels with enhanced properties in various fields through the existing and newlydeveloped techniques.
\end{abstract}

\section{Introduction}

In recent years, various kinds of carbon nano-structure materials have raised general interest among researchers from different fields. Graphene, as a representative two-dimensional (2D) layered material, has already attracted global attention for applications in sensors, catalysis, and environmental fields due

${ }^{a}$ School of Chemistry and Chemical Engineering, Chongqing University, Chongqing 400044, China. E-mail: stzhcq@163.com; Tel: +86-023-65102531

${ }^{b}$ School of Materials and Chemical Engieering, Tongren University, Tongren 554300, China

'Institute of Oceanology, Chinese Academy of Sciences, Qingdao 266071, China to the high thermal conductivity, transmittance, and electrical conductivity.$^{1-3}$ As a result, graphene has played a crucial role in manufacturing multifunctional graphene-based composites due to their encouraging characteristics. ${ }^{4-6}$ Therefore, graphene and its functionalized derivatives can be used as outstanding building blocks for self-assembly of functional carbon-based materials due to the unique two-dimensional (2D) structures such as 2D graphene films and $3 \mathrm{D}$ graphene/polymer composites. ${ }^{7-9}$

Nowadays, a variety of functional graphene-based composites fabricated by chemical modifications or non-covalent functionalizes have been reported. ${ }^{\mathbf{1 0}-12}$ However, the strong interaction of $\pi-\pi^{*}$ band structure between graphene sheets

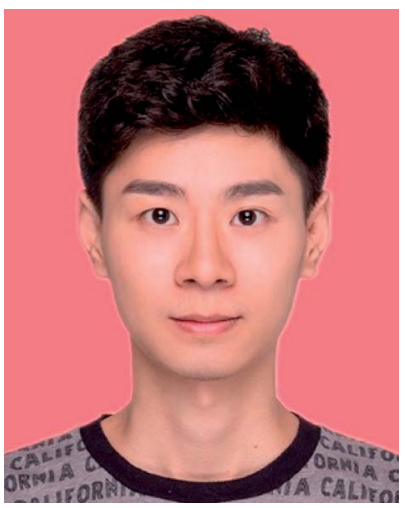

Hao Lu was born and raised in Sichuan Province, China. He received his bachelor degree in Chongqing University in 2013. In the same year, he joined Prof. Shengtao Zhang's research group to pursue his masters and doctorate studies at Chongqing University. He has been working in Weihua Li's group for two years in the Institute of Oceanology, Chinese Academy of Sciences, Qingdao, China. Currently, he works in the synthesis, measurement, and application of novel functional $2 D$ materials.

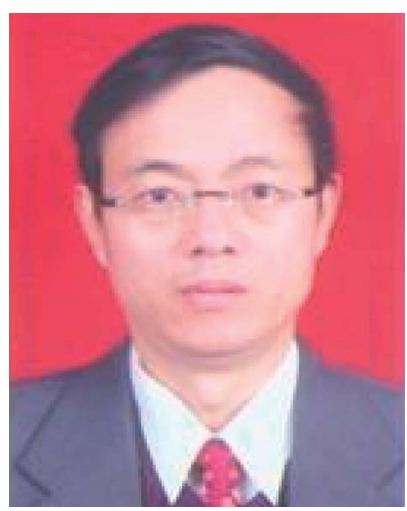

Prof./Dr Shengtao Zhang was born and raised in Sichuan Province, China. He obtained his $P h D$ in Chongqing University, 2004. He has been successively studying and working in the University of California, Berkeley, University of Bremen, and Moscow University during his research life. Up to now, he has published over 170 academic papers and two monographs. His current research is concentrated on corrosion and protection of materials, electrochemical analysis and measurements, and surface engineering of materials. 
makes them hydrophobic and easy to reunite. ${ }^{\mathbf{1 3}, \mathbf{1 4}}$ Besides, the direct application of graphene sheets still suffers from the poor stability. ${ }^{15,16}$ Therefore, public attention is thoroughly aroused as to the modified graphene nano-materials, which including chemical-modified and functionalized graphene. ${ }^{17-19}$ Among them, graphene oxide (GO) has been more frequently studied due to the abundant functional groups and excellent hydrophile. ${ }^{\mathbf{2 0 2 1}}$ At present, the preferred fabricating method of GO for the most of colleges and scientific institutions is the modified Hummer method, which has the advantages of high efficiency and security. ${ }^{22,23}$ Graphite powder, potassium permanganate and concentrated sulfuric acid are selected to assume reactants. ${ }^{\mathbf{1 4 2 4}}$ Eventually, GO is obtained after experiencing three reaction stages of the low, middle and high temperature in order.

As a typical kind of 3D macroscopic structure, hydrogels are consist of the loose and porous networks which possess huge potentials in electrochemical materials, catalysis, sensor, and water treatment especially industrial waste water owing to allowing the access and diffusion of ions or molecules. ${ }^{25-29}$ Besides, carbon nanotubes and GO sheets have been preliminary used as building blocks for the assembly of ordinary hydrogels or another kind of materials (aerogels). ${ }^{30}$ The freestanding graphene hydrogel functionalized with polydopamine can be used in water purification.

One of the most successful application of hydrogels were contact lenses in medicine. And researches of drugs sustainedrelease and fabrication of artificial lens had been developed rapidly from then on. At present, hydrogels are also frequentlyused in agriculture and sanitation materials as water absorbents or retaining agents due to the excellent character of retaining water. ${ }^{31-35}$ Meanwhile, the problem of water pollution has been intensified with the increasing population and development of industry. Therefore, hydrogels can be used to provide treatments for the effluents as adsorbents. ${ }^{36-39}$ What's

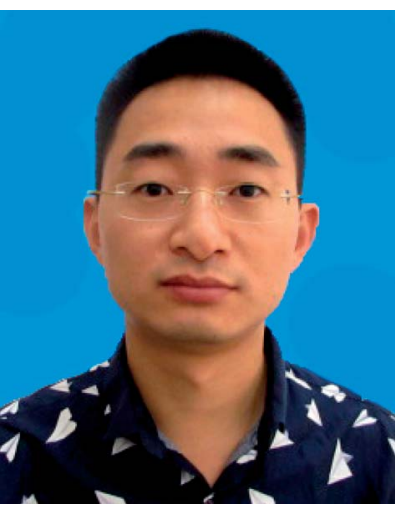

Prof./Lei Guo was born in Henan Province, China. He obtained his B.Sc. in Chemistry from Shangqiu Normal University and M.Sc. in Chemistry from Chongqing University, in 2010 and 2012 respectively. $\mathrm{He}$ received his Ph.D. degree in 2015 from Chongqing University, under the supervision of Prof. Shengtao Zhang. He is now working at the Tongren University of China. His research interests centre around a number of University based research projects from different disciplines such as corrosion research, hydrogels, health sciences as well as with collaborations with industry. He is also interested in computational chemistry. He has published over 40 papers in peer reviewed international journals, and two academic books. more, coating materials of cable, drilling lubricant, preservative wrapper of foods are also important applications of hydrogels. Last but not least, hydrogels can be applied to prepare the humidity sensors, moisture sensors, leakage detectors and other fine chemicals as well. ${ }^{40-43}$

In this review, we will summarize the applications of graphene-based composite hydrogels, with the aim of arousing the interest of the researchers in this field.

\section{Applications of hydrogels in various fields}

\subsection{Hydrogels as additives for delivering or controlling releasing of drugs}

Park and Qiu have introduced the fabrication and application of the environment-sensitive hydrogels for drug delivery. ${ }^{\mathbf{4 4}}$ Generally, hydrogels are networks of hydrophilic polymers that can swell in water and hold a large sum of water while maintaining the original structure. ${ }^{45}$ Therefore, hydrogels could protect the drug from the opposed environments, such as the presence of various enzymes and low $\mathrm{pH}$ in the stomach. Besides, hydrogels could also control the release of drugs by changing the structure in response to environmental stimuli. ${ }^{46,47}$

According to Shi's research, graphene oxide/poly(vinyl alcohol) (GO/PVA) composite hydrogel was prepared to act as a potential candidate for controlled drug release. ${ }^{48}$ Hence, it is obvious that the obtained composite hydrogel can be used for $\mathrm{pH}$ controlled selective drug release, which is also called $\mathrm{pH}$ sensitive. GO was prepared by the modified Hummers' method then dispersed. The obtained GO dispersion were added into PVA solution for next, and the mixture was shaken violently for seconds to form a gel. Afterwards, ultrasonic treatment was adopted to make the gelation process complete. ${ }^{\mathbf{4 9}}$ The influence of cross-linking agent concentration in the

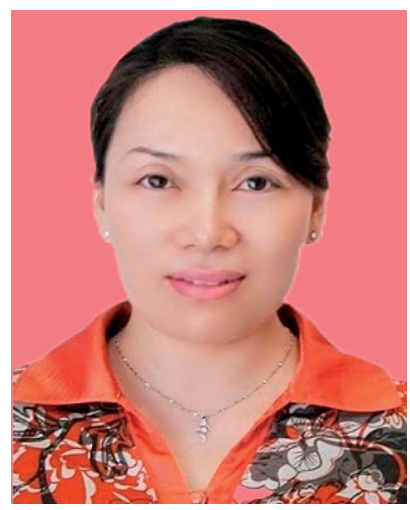

Prof./Dr Weihua Li was born and raised in Henan Province, China. She obtained her PhD in Ocean University of China, 2006. Then, she worked as a postdoctoral researcher in Key Laboratory of Marine Environmental Corrosion and Biofouling, Institute of Oceanology, Chinese Academy of Sciences, Qingdao, China from 2007. Up to now, she has published over 90 SCI articles and over $50 \mathrm{EI}$ articles, as well as five monographs. Her main research interests are on the corrosion mechanism in marine engineering and environmentally-friendly protective materials. 
gelation process was also studied in their paper. It is confirmed that the gelation process depends on PVA with various weight ratios to $\mathrm{GO}\left(r_{\mathrm{P} / \mathrm{G}}\right)$ strongly (Fig. 1A). As shown in Fig. 1B, the GO/ PVA composite hydrogel is gellable in acidic media as undergoing gel-sol transition under alkaline conditions. X-ray diffraction (XRD) and scanning electron microscope (SEM) were utilized to illustrate the patterns of lyophilized GO/PVA composites. The results reveal that the PVA component in the GO/PVA composite gel acts as a cross-linking agent. Moreover, Vitamin $\mathrm{B}_{12}\left(\mathrm{VB}_{12}\right)$ was chosen as the model drug for evaluating the releasing ability of GO/PVA hydrogel, due to the biocompatibility and $\mathrm{pH}$-sensitivity. Then it indicates that the GO/PVA hydrogel is efficient for controlled drug release with a fairly low gelator concentration.

As we can see from the above two researches, hydrogels can help controlling the release of functional drugs by changing construction themselves in response to environmental stimuli, such as different body organs, body fluid or diseased tissue. ${ }^{50}$ Performance of delivering and controlling releasing drugs become more outstanding in graphene-based hydrogels, which had been proved in experiments. Graphene-based hydrogels could contain the gelation status in a relatively stable environment. The status of hydrogels would change from gelation to solution after changing of $\mathrm{pH}^{.{ }^{51}}$ Functional drugs wrapped in graphene-based hydrogels would be released gradually. Graphene-based hydrogels could not only protect drugs changing characters by digestive juice, but also control the speed of drugs' releasing by regulating the ratio of composition materials of hydrogels. In subsequent study, small molecules, especially novel biologic organic molecules would be available to become additions in different kinds of functional graphenebased hydrogels, which can obviously increase the biocompatibility, degradability and environment friendly performance. ${ }^{52}$

\subsection{Hydrogels as adsorbents for water purification}

Huang et al. have reported a facile approach to prepare a kind of graphene-based hydrogels (see Fig. 2). ${ }^{53}$ In their research, agarose (AG) was employed as a stabilizer and reducing agent to form the structure of hydrogels. The GO-AG hydrogel was fabricated by the crosslinking of AG molecules, due to the adsorption on the surface of GO through a strong hydrogen bonding effect and hydrophobic interactions with the surface functional groups such as carboxyl, hydroxyl, and epoxyl of AG. The SEM images and FT-IR spectra explain that the crosslinking of AG on the surfaces of graphene sheets makes it interlace to form a 3D microstructure. Besides, cracks and holes were found in the interior of hydrogels, which demonstrated that the loose
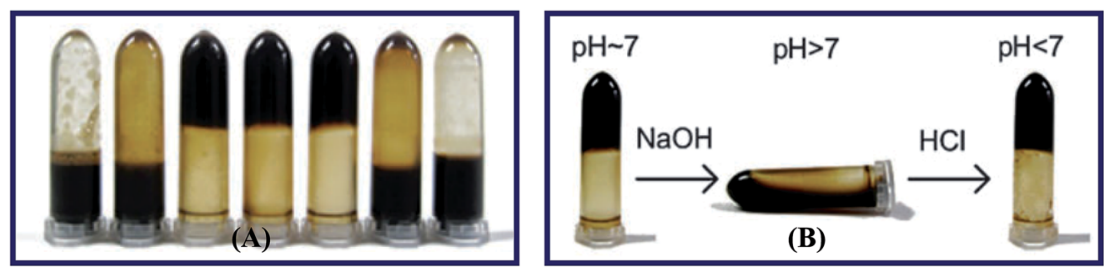

Fig. 1 (A) Photographs of GO/PVA mixtures with different content ratio $\left(r_{\mathrm{P} / \mathrm{G}}\right)$. From left to right, $r_{\mathrm{P} / \mathrm{G}}=1: 1,1: 1.5,1: 2,1: 5,1: 10,1: 20,1: 40$. (B) Photographs of the $\mathrm{pH}$-induced gel-sol transition. ${ }^{48}$

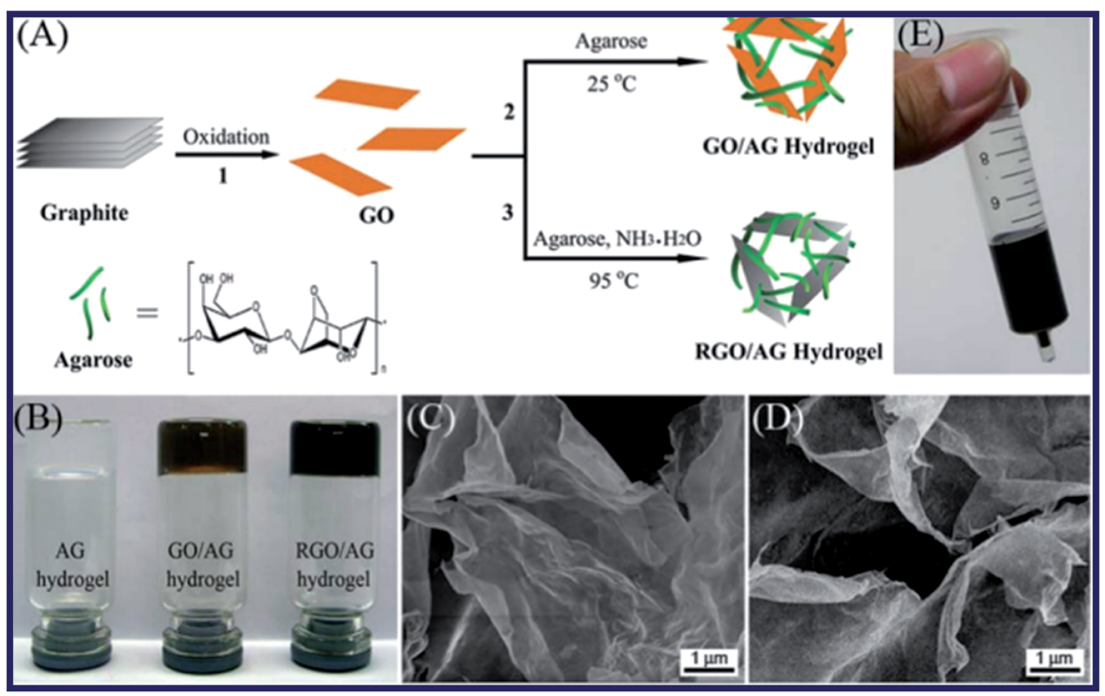

Fig. 2 (A) Illustration showing the routes for the preparation of graphene-AG hydrogels. The chemical structure of agarose is shown at the bottom of (A). (B) Photograph of AG, GO-AG, and RGO-AG hydrogels, respectively. (C and D) SEM images of GO-AG and RGO-AG hydrogels. (E) Photograph of the fabricated gel column loaded with the RGO-AG hydrogel. ${ }^{53}$ 
structures were obtained after interaction of AG and graphene sheets. Furthermore, the graphene-AG hydrogels were applied to test the dye adsorption ability from water due to the large specific surface area of graphene and the porous structure of the hydrogels. As a kind of triphenylmethane dyes, MG was chosen as a model organic dye to study the dye adsorbing ability of the graphene-AG hydrogels. Furthermore, the adsorption efficiency of the hydrogels was obtained from UV-vis spectra of the water with MG. Over $50 \%$ of MG had been adsorbed after $12 \mathrm{~h}$, and the adsorption quantity of MG increased to $90 \%$ after 7 days. The results showed an excellent adsorbing effect of graphene-AG composite hydrogel compared with the pure AG hydrogel. What's more, other graphene-based materials such as GO and reduced graphene oxide (RGO) were investigated to evaluate the adsorption effect for more dyes in their other researches. ${ }^{\mathbf{5 4}}$

Bai's research ${ }^{55}$ have proposed an eco-friendly graphene oxide-chitosan (GO-CS) composite hydrogel as a new kind of adsorbent for water purification. The GO-CS hydrogels were fabricated via self-assembly of GO sheets and CS chains. A loose 3D network structure consisting of GO sheets crosslinked by CS was observed in the composite hydrogel from the SEM image. The porous structure of the hydrogel assists the diffusion of adsorbates inside the hydrogel, increasing the adsorption capacity of the GO-CS hybrid. Thus, the obtained hydrogel owned excellent adsorption capacity of different dyes and heavy metal ions. Afterwards, methylene blue (MB) and eosin Y were selected to evaluate the adsorption capacity of GO-CS hydrogels (see Fig. 3). It was found that the adsorption capacity of the

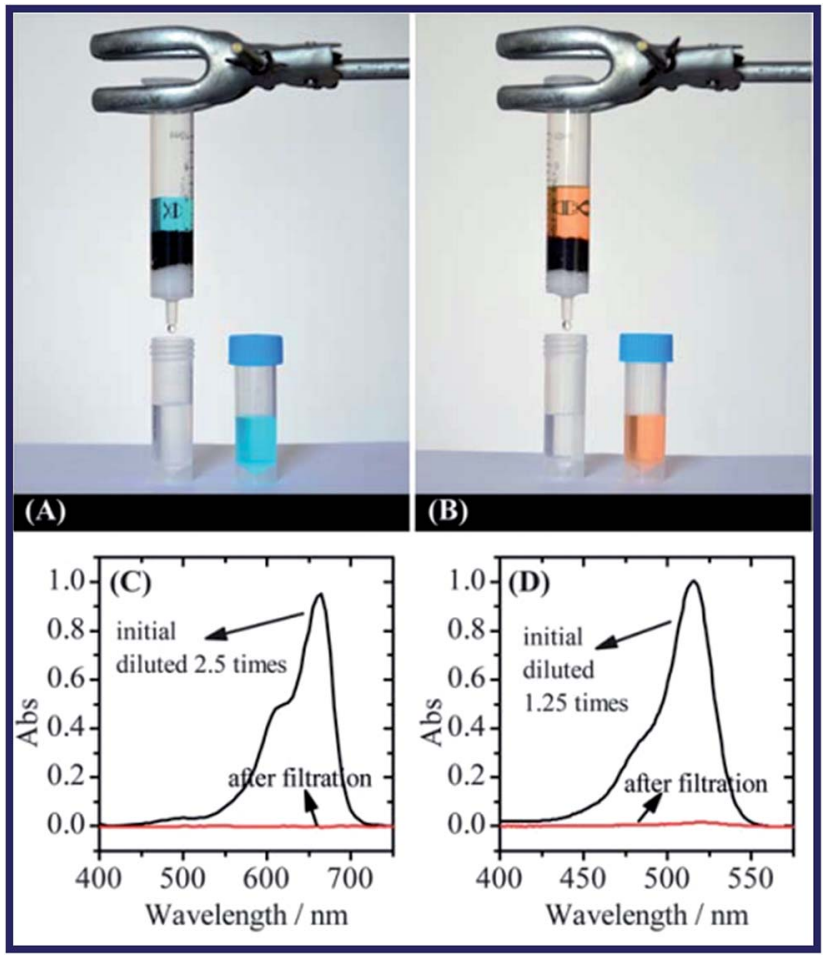

Fig. 3 Removal of dyes from water by filtration. ( $A$ and $B$ ) Images of the apparatus used for filtration and the solution before and after filtration. ( $C$ and D) Absorption spectra of the $M B(C)$ and eosin $Y(D)$ solution before and after filtration. ${ }^{55}$ hydrogel would change with the composition of it. More specifically, a higher content of GO leads to higher adsorption capacity towards $\mathrm{MB}$, while a higher content of CS leads to higher adsorption capacity towards eosin Y as well. What's more, the GO-CS composite hydrogels also shows a nice adsorption capacity towards some heavy metal ions, such as $\mathrm{Cu}$ (II) and $\mathrm{Pb}$ (I). As a consequence, the excellent adsorption capacities were attributed to the coordination of GO and CS with various metal ions.

Duan et al. presented a one-step method to prepare the polydopamine-modified graphene hydrogel. ${ }^{56}$ The method is based on the spontaneous process of polymerization of dopamine and the self-assembly ability of graphene nanosheets inside the porous hydrogel structures. Besides, the dopamine served as surface functionalized agents and reductant in the hydrogels. The polydopamine functionalized graphene hydrogel (PDA-GH) was prepared by the procedure as followed, after GO was obtained by the modified Hummers' method. ${ }^{57}$ Dopamine was added into the GO aqueous dispersions to obtain a homogeneous mixture. Furthermore, the product PDA-GH was formed after the mixture above reacting at $60{ }^{\circ} \mathrm{C}$ in static conditions. Hydrothermally synthesized graphene hydrogel (HT-GH) was fabricated by hydrothermal measurements of GO aqueous solution in a Teflon-lined autoclave at $180{ }^{\circ} \mathrm{C}$ for $12 \mathrm{~h}$. The target product HT-GH would be obtained after the autoclave cooling to the room temperature naturally. SEM, atomic force microscopy (AFM) and X-ray photoelectron spectroscopy (XPS) were employed to offer the materials characterization. Besides, adsorption experiments were also carried out to investigate the adsorption situation of $\mathrm{Cd}(\mathrm{II}), \mathrm{Pb}(\mathrm{II})$, rhodamine $\mathrm{B}$ and $p$-nitrophenol of the PDA-GH and HT-GH (see Fig. 4). The results showed that the adsorption capacity for various pollutants was obviously enhanced of PDA-GH and HT-GH. Overall, the graphene-based hydrogels fabricated by the one-step method with low-cost had effectively improved the inadequacy of other carbon nano-materials in water purification, including low adsorption capacity, stubborn residue, and intricate work and recovery mechanism. Moreover, the obtained capable hydrogels could own high adsorption capacity after a mass of adsorption-desorption cycles and be easily regenerated by facile and accessible reagents. Therefore, PDA-GH and HT-GH might work as a novel and efficient freestanding adsorbent for water purification.

Liu et al. have prepared the Ni-doped graphene/carbon cryogels (NGCC) by adding formaldehyde and resorcinol to the suspension of GO, which was based on the freeze-drying of the hydrogel precursor. ${ }^{58}$ SEM, TEM, FT-IR spectra and XRD were utilized to characterize the NGCC. NGRC had been transformed to NGCC after carbonization experiment (Fig. 5), which showed a remarkable mechanical properties of keeping the original shape after pressed by nearly 4000 times the mass of itself. Furthermore, oil, organic solvent and methyl blue (MB) adsorption tests were performed to evaluate the adsorption capacity of the cryogel. Results indicated that the NGCC had completed the adsorption process in $1 \mathrm{~min}$ due to the superwetting behaviour for oils and organic solvents. As a consequence, excellent recycling performance of the NGCC was 


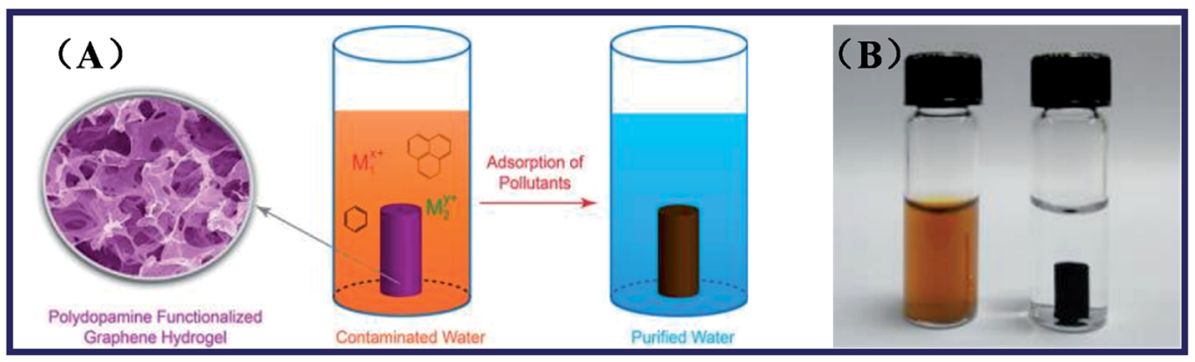

Fig. 4 (A) Microstructure and adsorption process of the graphene hydrogel, and (B) photograph of GO dispersion mixed with dopamine (left) and the monolithic material of PDA-GH (right). ${ }^{56}$

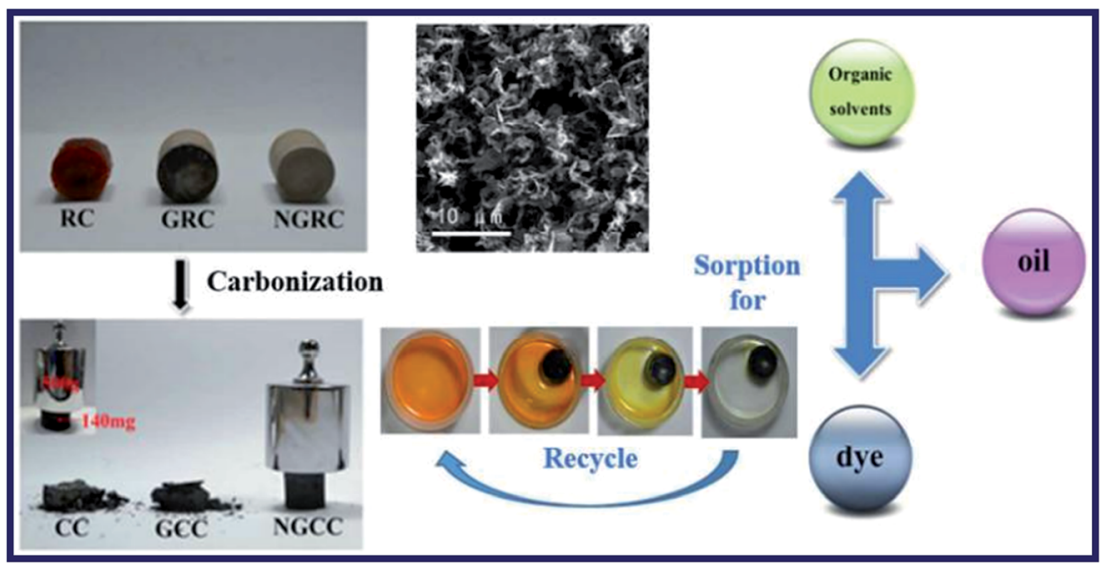

Fig. 5 Characterization, carbonization, adsorption for organic solvents, oil and dye, and recycle of RC, GRC and NGRC.58

implied that over $90 \%$ of the adsorption capacity of NGCC for oils could be maintained after 7 cycles. Besides, the typical MB adsorption capacity-time curves of the cryogel powders were obtained after adsorption measurements. The adsorption curves have reached equilibrium in a short time, which indicated that the introduction of graphene had changed the morphology of the cryogels, and enhanced the surface areas and porosities. As a consequence, all the phenomena have contributed to an obvious improvement in adsorption capacity of the hybrids. And the NGCC fabricated with an inceptive GO concentration of $6 \mathrm{mg} \mathrm{mL} \mathrm{mL}^{-1}$ shows the strongest adsorption capacity of MB among the experiment samples investigated.

Water treatment has attracted fully attention in recent studies. One of the most intuitionistic and efficient measures to depurate water is adsorption. ${ }^{59,60}$ Heavy metal ions, organic solvents, oil and dye are the most common water pollutants, which could be adsorbed by novel graphene-based hydrogels. According to the above researches, different additions, such as agarose, chitosan and Ni-doped cryogels, could signally improve the adsorption and processing capacity of graphenebased hydrogels. ${ }^{\mathbf{6 1 , 6 2}}$ In addition, adsorption efficiency after several circulations would be comparatively ideal according to the results of the above experiments. Therefore, making the adsorption efficiency staying in an excellent status after decades (or more) of circulations, or increasing the value of adsorption efficiency by doping different functional materials would be more challenging in subsequent researches. Besides, control of the cost of reagents and additions is also pivotal in application. ${ }^{63,64}$

\subsection{Hydrogels as adsorbents of dyestuffs in various fields}

Fan et al. have investigated a novel GO/sodium alginate (SA)/ polyacrylamide (PAM) ternary nano-composite hydrogel with excellent mechanical properties, which was polymerized of acrylamide (AAm) and SA through free-radical polymerization in the presence of GO in aqueous solution (see Fig. 6). ${ }^{65}$ The hydrogels were prepared into a column with a diameter of $24 \mathrm{~mm}$ and a length of $20 \mathrm{~cm}$ to accept compressive and tensile tests, for evaluating the mechanical properties. Results revealed that the as-prepared GO/SA/PAM ternary hydrogel with $5 \mathrm{wt} \%$ of GO displayed a compressive stress of $1.543 \mathrm{MPa}$ at a $70 \%$ compressive deformation. Besides, the tensile strength and modulus of the obtained hydrogel were proved to be up to 201.7 and $30.8 \mathrm{kPa}$, respectively. Meanwhile, excellent selfrepairability and elasticity were also found towards the ternary hybrid hydrogel. Additionally, the GO/SA/PAM composite hydrogels exhibited great adsorption capacities for a series of dyes as followed. As shown in Fig. 7, the dye adsorption capacities of the as-prepared composite hydrogel were enhanced significantly with the introduction of GO.

Zhang et al. have investigated a kind of magnetic graphene nano-composite with great solubility in water, which was synthesized via a copper catalyzed azide-alkyne cycloaddition 


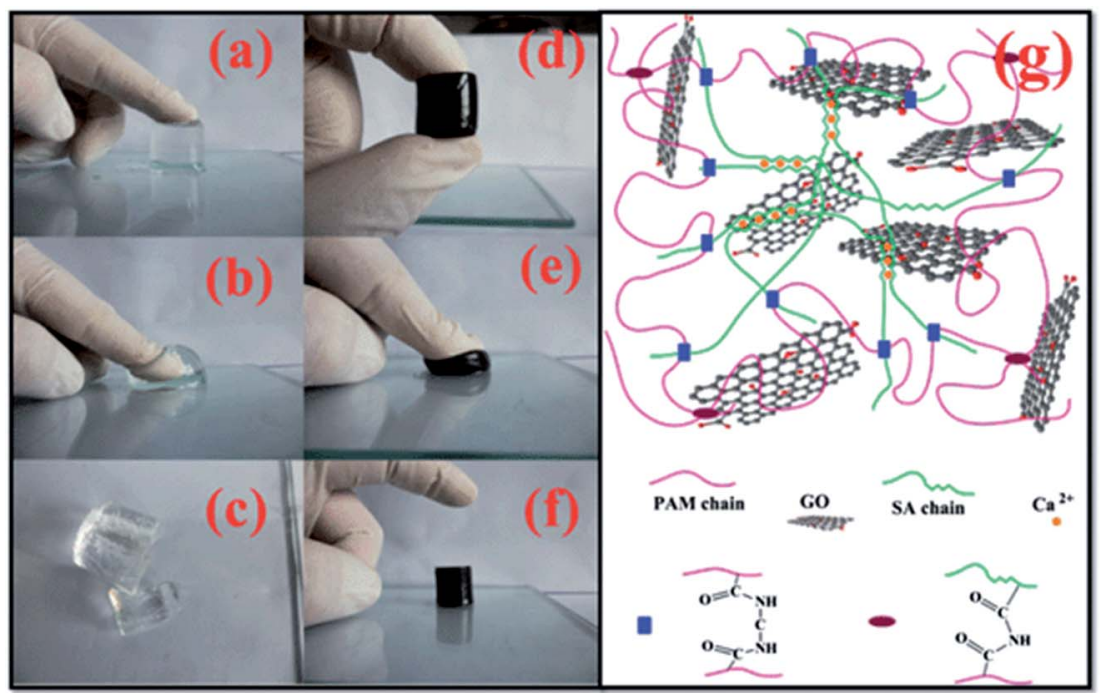

Fig. 6 (a-f) Photographs of PAM and G5S1P2 hydrogels under pressure, (g) schematics of GO/SA/PAM ternary composite hydrogels. ${ }^{65}$

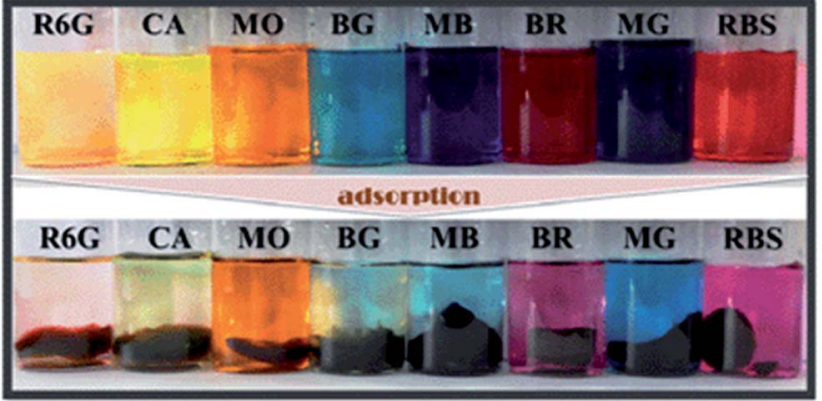

Fig. 7 Photographs of different dye solutions before and after adsorption by the GO/SA/PAM composite hydrogels. ${ }^{65}$

reaction and then modified with polyacrylic acid (PAA). ${ }^{66} \mathrm{AFM}$, TEM, XRD and Raman spectra were employed to characterize the surface morphology and structural components. The high surface area, superparamagnetism and great complex properties made the $\mathrm{PAA} / \mathrm{GO} / \mathrm{Fe}_{3} \mathrm{O}_{4}$ nano-composite useful as a nanoadsorbent for the recyclable removal of $\mathrm{Cd}^{2+}, \mathrm{Pb}^{2+}$ and $\mathrm{Cu}^{2+}$ ions from aqueous solution. ${ }^{67}$ Besides, the nano-composite hydrogel was added into a $50 \mathrm{~mL}$ plastic vial with heavy metal ion solution at room temperature to measure the adsorption capacity. Results showed that the hydrogel was quite easy to separate and recycle because of the super paramagnetism of $\mathrm{Fe}_{3} \mathrm{O}_{4}$ and the removal efficiency of the hydrogel for $\mathrm{Cd}^{2+}, \mathrm{Pb}^{2+}$ and $\mathrm{Cu}^{2+}$ ions was still over $85 \%$ after 5 cycles. ${ }^{68}$

Zhang et al. have reported a new kind of multifunctional titanium dioxide $\left(\mathrm{TiO}_{2}\right)$-graphene nano-composite hydrogel (TGH), which was fabricated by a facile hydrothermal approach and investigated as supercapacitor, photocatalyst, and reusable adsorbent. ${ }^{37} \mathrm{~A}$ certain amount of $\mathrm{TiO}_{2}$ nanoparticles was added to the homogeneous GO suspension and kept in ultrasonic exfoliation for $1 \mathrm{~h}$. Afterwards, the compound solution was sealed in a autoclave and kept in quiescence under $180^{\circ} \mathrm{C}$. Black and columnar hydrogel could be obtained after letting the autoclave cool down in room temperature. And the size of the TGH may change with different volume of graphene aqueous dispersion. ${ }^{69}$ SEM, TEM, FT-IR, XPS, and XRD measurements were taken to characterize the obtained hydrogel, which indicated that the pore walls of TGH consist of thin layers of stacked graphene sheets, while the spherical nano-structured $\mathrm{TiO}_{2}$ particles were largely anchored onto the graphene nanosheets. The introduction of $\mathrm{TiO}_{2}$ nanoparticles on graphene sheets has functionalized the TGH and acted as a barrier to prevent the aggregation of the graphene sheets due to the growth of the specific surface area of TGH. ${ }^{70}$ What's more, dye adsorption and photocatalytic activity tests were performed after characterization. In the presence of TGH, the absorption capacity of MB is almost 3 or 4 times more than in the presence of $\mathrm{GH}$ or $\mathrm{TiO}_{2}$ nanoparticles, respectively, which reveals that the TGH possesses the higher dye adsorption capacity in the tests.

Studies have shown that more and more kinds of dyestuffs could be absorbed by different hydrogel hybrids..$^{71,72}$ Especially, in the presence of graphene-based materials, the absorption capacity is obviously increased. Excellent mechanical capacity of hydrogel makes the connection more closely between graphene (and other functional additions) and hydrogel itself. ${ }^{73}$ Different kinds of dyestuffs and heavy mental ions exist in various fields, so the hydrogel could be a preferred choice with wide-range and large-adsorbance. ${ }^{74}$ In addition, graphene and its functional derivatives could signally prevent the aggregation of the graphene sheets in complex environment. So enormous potential of graphene-based hydrogels will surely be more frequently studied in absorption. ${ }^{75}$

\subsection{Hydrogels used in energy storage device}

Lu et al. have provided us with a novel reduced graphene oxide/ polypyrrole composite hydrogel with great electrochemical performance and compression, which could be used in efficient energy storage device. ${ }^{76}$ As shown in Fig. 8, reduced graphene oxide (rGO) and polypyrrole (PPy) were combined by 


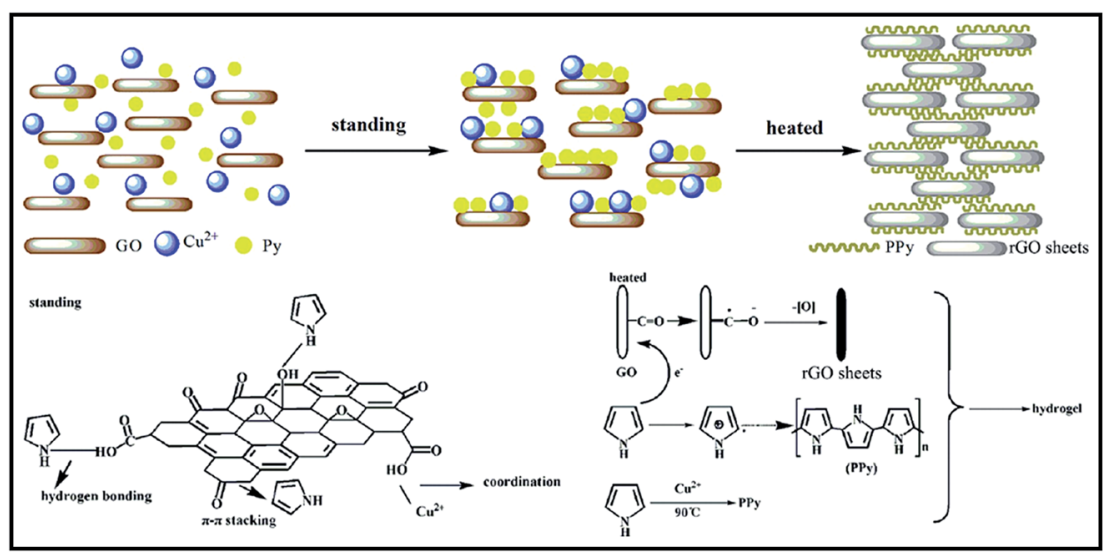

Fig. 8 Schematic diagram of the preparation process of rGO/PPy hydrogel. ${ }^{76}$

a self-assembly process at room temperature. Afterwards, an oxidation polymerization was triggered by both of the reactants mentioned above to form a cross-linked and hierarchical porous 3D structure. The obtained hydrogel with 3D structure delivered an excellent compression-tolerant capacity and a high specific capacitance. Particularly, over $80 \%$ of the capacitance value could be maintained after 5000 charge-discharge cycles. Therefore, it is obvious that great potential applications of rGO/ PPy hydrogels in energy devices will draw much more attention of researchers in the future years. In addition, rGO conducting polymer composite invariably own the poor mechanical strength performance. ${ }^{77}$ It could be thought that the increase amount of PPy might help forming the denser structure, as well as stronger interaction between rGO and PPy chains, resulting in the much stronger mechanical property and the higher electrochemical performance at large current.

Lee $e t a l$. have designed a 3D porous structure hydrogel for applying in a high-performance asymmetric supercapacitor device. ${ }^{78}$ The extraordinary structure was designed based on carbon dot supported copper sulphite (CuS)-decorated graphene oxide (GO) hydrogels, which delivered to improve the cyclic stability, specific capacitance and energy density of CuS as well as GO based supercapacitors. The hydrogel was prepared by a simple hydrothermal reaction using teflon-lined stainless steel autoclave at $180{ }^{\circ} \mathrm{C}$ for $12 \mathrm{~h}$ and then optimized through different characterization. Carbon dot could significantly help to bind strongly GO with CuS in the 3D structure as a stabilizer for the CuS. Hydrogels obtained from the above process delivered high specific capacitance of $920 \mathrm{~F} \mathrm{~g}^{-1}$ at a current density of $1 \mathrm{~A} \mathrm{~g}^{-1}$. Most importantly, they had brought up an idea that the optimal hydrogel could be used as a positive electrode for the preparation of asymmetric supercapacitor along with rGO as the negative electrode. After electrochemical chargedischarge measurements, the supercapacitor based on obtained hydrogel exhibited a extremely high energy density up to $28 \mathrm{~W} \mathrm{~h} \mathrm{~kg}^{-1}$ and remained up to $90 \%$ specific capacitance after 5000 cycles. Results indicate that their research would provide a new insight of GO or CuS based composite with 3D structure for supercapacitor in advanced energy storage applications.
Li et al. have prepared the nitrogen/sulfur co-doped and hierarchical porous graphene hydrogels (DHGHs) via a facile self-assembly process. ${ }^{79}$ The schematic for the assembling process and internal structure of the supercapacitor device was shown in Fig. 9. Results of experiments had shown that the $\mathrm{pH}$ values in preparation process significantly affect the structures of products and directly applied as binder-free electrodes to assemble full-cell supercapacitor devices. After the chargedischarge experiments, it is surprising that the obtained hydrogel exhibits a specific capacitance of $251 \mathrm{~F} \mathrm{~g}^{-1}$ at a current density of $0.5 \mathrm{~A} \mathrm{~g}^{-1}$. Besides, the results also showed the rectangular cyclic voltammetry shape at a high scan rate of $3000 \mathrm{mV}$ $\mathrm{s}^{-1}$ and symmetrical galvanostatic charge-discharge curves at $100 \mathrm{~A} \mathrm{~g}^{-1}$, which delivers a high energy and power density, as well as a specific capacitance. Furthermore, the hydrogel based device also presents superior cycling stability of $96.8 \%$ retention after 2000 cycles. Therefore, the unique self-assembly graphene based hydrogel could be applied as promising candidate for high energy density supercapacitors at high rates.

Zhao et al. have fabricated a kind of graphene/ polyaniline@carbon cloth (GP@cc) composite by a one-step electrochemical co-deposition method. ${ }^{80}$ Generally, the applications of supercapacitors are greatly limited due to their low conductivity, which is actually restricted by the effect of binder. While in their work, carbon cloth was dried under vacuum at $60^{\circ} \mathrm{C}$ to assume the working electrode, along with platinum $(\mathrm{Pt})$ foil as the counter electrode, and $\mathrm{Ag} / \mathrm{AgCl}$ as the reference electrode. Then, $12 \mathrm{~h}$ of constant stirring was required to form the two pieces of GP@cc composites. The obtained composite based on graphene and polyaniline exhibited outstanding electrochemical properties with a high specific capacitance of $793 \mathrm{~F} \mathrm{~g}^{-1}$ at a current density of $0.5 \mathrm{~A} \mathrm{~g}^{-1}$ and excellent cycle stability. What surprising us is the device possessed a retention of $81 \%$ of initial specific capacitance after 10000 cycles. As a result, this binder-free and flexible supercapacitor with superior electrochemical performance would meet the increasing demands in energy storage field, such as electronic paper, roll-up displays and other wearable electronic products.

In recent decades, supercapacitor has become one of the most promising devices to store electrical energy for the 


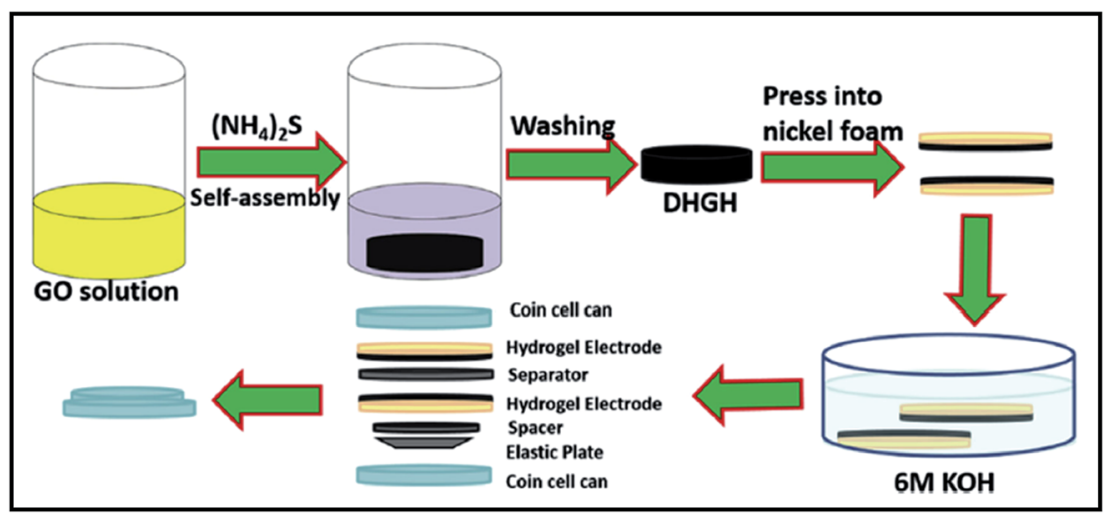

Fig. 9 Schematic of the preparation of DHGHs and the assembly process of the two-electrode system supercapacitor. ${ }^{79}$

next-generation new type electronics due to the high power density, fast charging capabilities and long cycle life in wide applications, such as backup energy, electric vehicles and other portable power supply. Moreover, graphene with novel 3D structure i.e. hydrogels have attracted extensive interests in energy storage because of the combination of extremely high electrical conductivity and superior mechanical strength of graphene as well as the porous structure and high specific surface area. The studies mentioned above have given some novel and feasible methods of preparation of graphene-based hydrogels. However, problems still exist in improving the retention of cycle stability over more charge-discharge cycles, as well as decreasing the difficulty of application of the latest wearable electronic products.

\subsection{Other applications of graphene-based hydrogels}

Shi et al. have prepared the graphene oxide/conducting polymer (GO/CP) composite hydrogels by in situ chemical polymerization of corresponding aromatic monomers in aqueous dispersions of $\mathrm{GO}$ sheets. ${ }^{29} \mathrm{GO} /$ polyaniline (PANi), GO/polypyrrole (PPy) and GO/poly(3,4-ethylenedioxythiophene) (PEDOT) were all fabricated via this method, and the mechanism of gelation was investigated in their report. After characterization and gas sensing tests, the GO/PPy composite hydrogels were proved to have quite low critical hydrogel concentrations, high electrical conductivity and storage capacity, and strong electrochemical activity among the three types above. Furthermore, a freshly prepared gas sensor which was obtained based on a typical GO/PPy hydrogel also exhibited high sensitivity towards ammonia gas. ${ }^{81}$

Liu et al. have prepared a type of polyvinyl alcohol (PVA) hydrogels which could be used as promising biomaterials in biomedical and tissue engineering, ${ }^{82}$ with coordination of GO. A $36 \%$ improvement of compressive strength and $132 \%$ increase in tensile strength appeared with the addition of $0.8 \mathrm{wt} \%$ of GO compared to pure PVA hydrogels, which indicated that the mechanical performances of GO/PVA hydrogels were significantly enhanced. ${ }^{83}$ The cell compatibility measurements of the hydrogels in their paper were rarely reported at present. After 1 day's observation, most of the experimental cells adhered to the surface of the GO/PVA hydrogels. Then the cells were almost flat and spreading after 3 days. Besides, no differences in the morphology or number of the cells were observed among the pure PVA hydrogel and GO/PVA hybrid hydrogel 5 days later, which showed no effect on the toxicity of hydrogels was existed after introducing the certain amount of GO. Therefore, the GO/PVA hydrogel reported in the paper could have various potential applications as biomaterials. ${ }^{84}$

Kuang et al. have reported a kind of 3D porous nitrogendoped graphene hydrogels (N-RGOH) as supercapacitor electrodes in ionic liquid electrolyte (Fig. 10).$^{85}$ SEM, XRD and XPS were utilized to show that the N-RGOH displayed a large specific surface area and high nitrogen content. A two-electrode symmetric supercapacitor was prepared in a Swagelok cell for evaluating the electrochemical properties of the hydrogel. Besides, both the power density and energy density were higher than the N-RGO and RGOH based supercapacitor, which indicated that the N-RGOH displayed an excellent capacitive performance. Furthermore, after the long-term cyclic stability tests, the N-RGOH had shown great cycling stability with a slight decrease $(\sim 13 \%)$ in the specific capacitance after 5000 cycles. In summary, the introduced doped $\mathrm{N}$ in the hydrogel had offered redox reaction to generate pseudocapacitance. And the addition of graphene, which had replaced a certain amount of $\mathrm{N}$ atoms, could effectively improve the electric conductivity of graphene. Therefore, the supercapacitive properties of the N-RGOH had been enhanced by $\mathrm{N}$-doping, and the particular 3D porous structure had proved a great rate performance of the $\mathrm{N}-\mathrm{RGOH}$ supercapacitor because of allowing the rapid charge and mass transfer (Fig. 11).

Zhao et al. had developed a novel fluorescent sensing platform based on GO hydrogel via a facile and fast gelation process. ${ }^{86}$ The adenosine and aptamer were utilized as the cocrosslinkers to connect the different GO sheets and then form the 3D structure after characterized by XRD and SEM. Oxytetracycline (OTC) was used as the detective target to measure the degree of fluorescence restoration of the GO-based hydrogel. A linear response for OTC of $25-1000 \mu \mathrm{g} \mathrm{L}^{-1}$ and a limit of quantitation of $25 \mu \mathrm{g} \mathrm{L}^{-1}$ of the hydrogel were obtained after a series of detection tests. Furthermore, the tetracycline derivatives with similar structure was also utilized to evaluate 


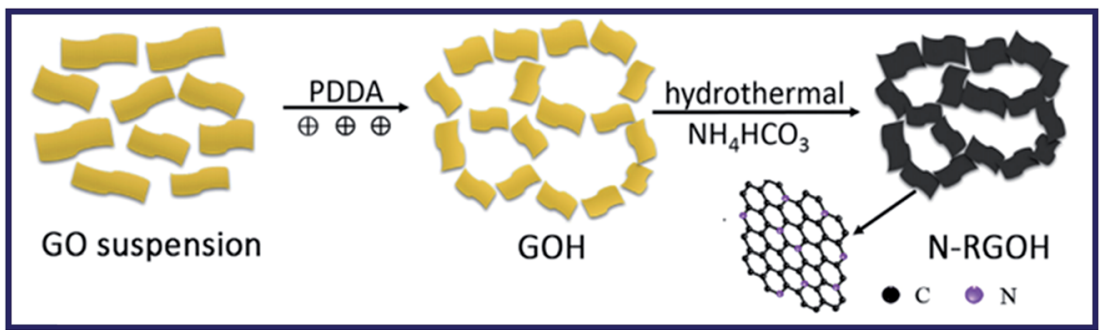

Fig. 10 Schematic diagram of the formation mechanism for the nitrogen doped graphene hydrogel. ${ }^{85}$
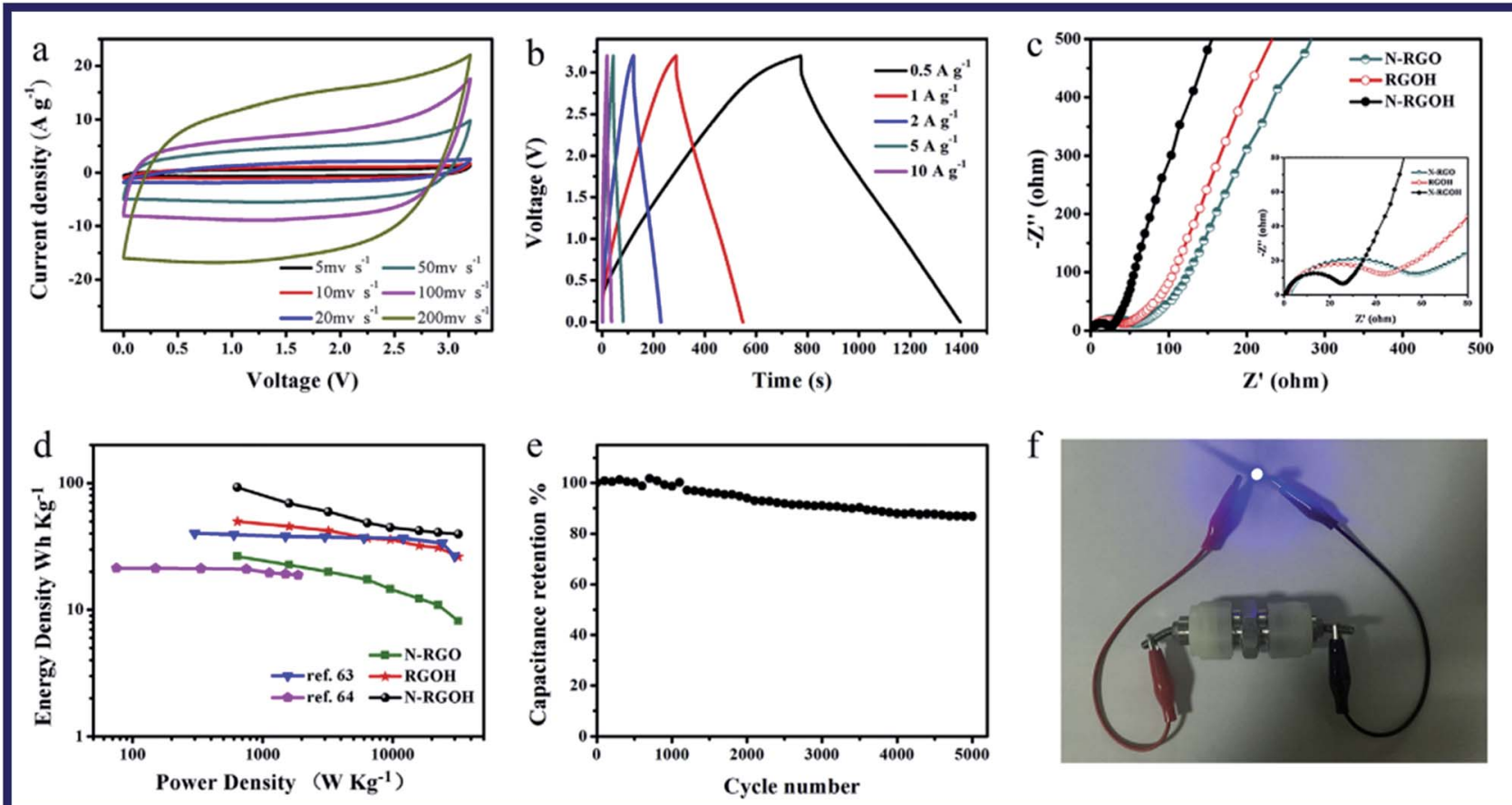

Fig. 11 Electrochemical performance of the N-RGOH electrode in a two-electrode system (a) CV curves at various scan rates, (b) galvanostatic charge/discharge curves at various current densities, (c) Nyquist plots of the N-RGO, RGOH and N-RGOH supercapacitors in [BMIM]PF 6 electrolyte, (d) Ragone plot of the symmetrical supercapacitor, (e) cycling stability at a constant scan rate of $100 \mathrm{mV} \mathrm{s}^{-1}$ over 5000 cycles, and (f) image of a LED powered by the N-RGOH based symmetrical supercapacitor. ${ }^{85}$

the specificity and anti-interference ability. Results showed that the fluorescent emission intensity increased obviously in response to OTC at $800 \mu \mathrm{g} \mathrm{L}^{-1}$, while no obvious responses were observed for other derivatives at the same concentration. Besides, the prepared developed sensor gave a similar response in the mixed derivatives solution compared with pure OTC solution, which forcefully proved the superior specificity and anti-interference ability. Eventually, the detective tests of OTC in real water samples also validated the excellent reproducibility of the detective performances of the hydrogel.

Xiong et al. have reported a novel method to fabricate anisotropic graphene-based cellular films with an interlinked microstructure, which exhibited both extraordinary toughness and high strength (Fig. 12) ${ }^{87}$ High in-plane rigidity and outstanding out-of-plane flexibility of the individual graphene sheet were improved to be fully exploited. Besides, rheological and rheo-optical measurements were adopted to evaluate the enhancement of toughness and strength, which were realized by a synergistic cooperation principle. They pointed out that the unique architecture of the obtained hydrogel could bear stress through tensile strain of the graphene sheets with anisotropy and dissipated energy through bending deformation of the graphene sheets with net structure. In summary, the graphenebased hydrogel developed in their paper can be used in various areas where the superior mechanical performances are in need.

Hur et al. have designed a novel glucose sensor based on $\mathrm{Co}_{3} \mathrm{O}_{4}$ nanoflowers and 3D GO hydrogel with highly sensitive enzyme-free via hydrothermal synthesis, which could be applied in controlling environmental pollution and influence of fast-food. ${ }^{88}$ As given in Fig. 13, cobalt(II) acetate tetrahydrated, urea and PVP were dissolved in deionized water, stirred and kept at $95{ }^{\circ} \mathrm{C}$ for hours to fabricate the $\mathrm{Co}_{3} \mathrm{O}_{4} \mathrm{NF} / \mathrm{GOH}$. The samples were mixed and transferred to a Teflon-lined autoclave with a stainless-steel shell at $105^{\circ} \mathrm{C}$ to fabricate the $3 \mathrm{D}$-structure 


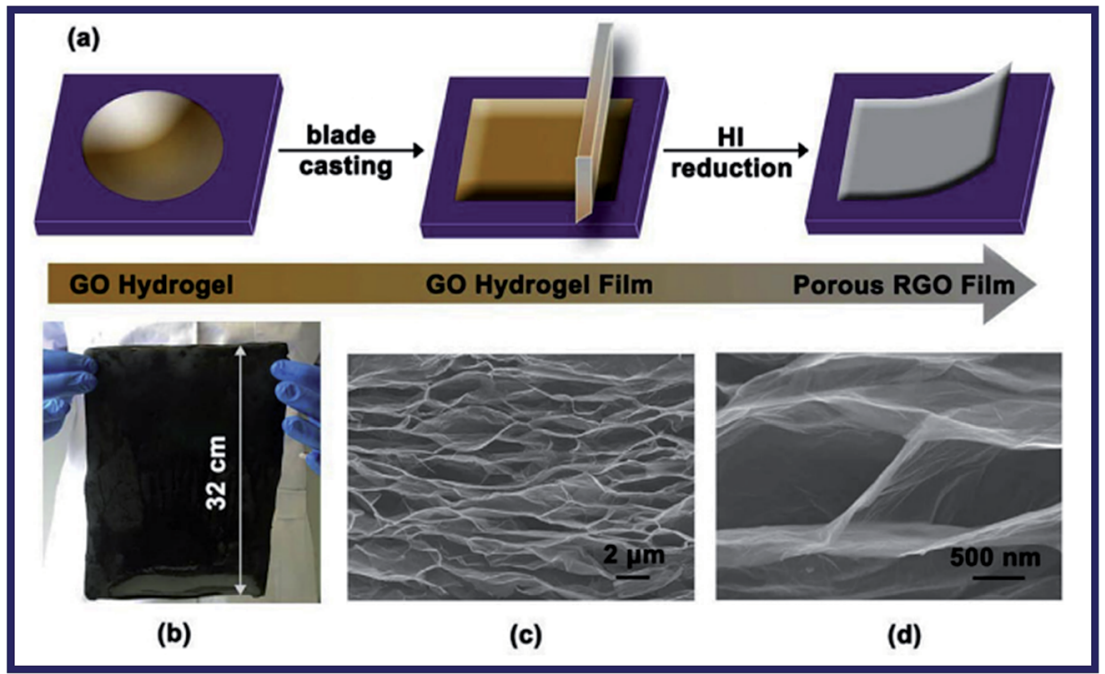

Fig. 12 Fabrication strategy and images of the porous RGO film: (a) schematic illustration showing the preparation process of the RGO film through blade-casting and reduction of GO hydrogel. (b) Photograph of a large piece of RGO film with $32 \mathrm{~cm}$ long and $24 \mathrm{~cm}$ wide. (c and d) Cross-sectional SEM images of the freeze-dried RGO films prepared from the GO hydrogel with the concentration of $8 \mathrm{mg} \mathrm{mL}^{-1} .{ }^{87}$

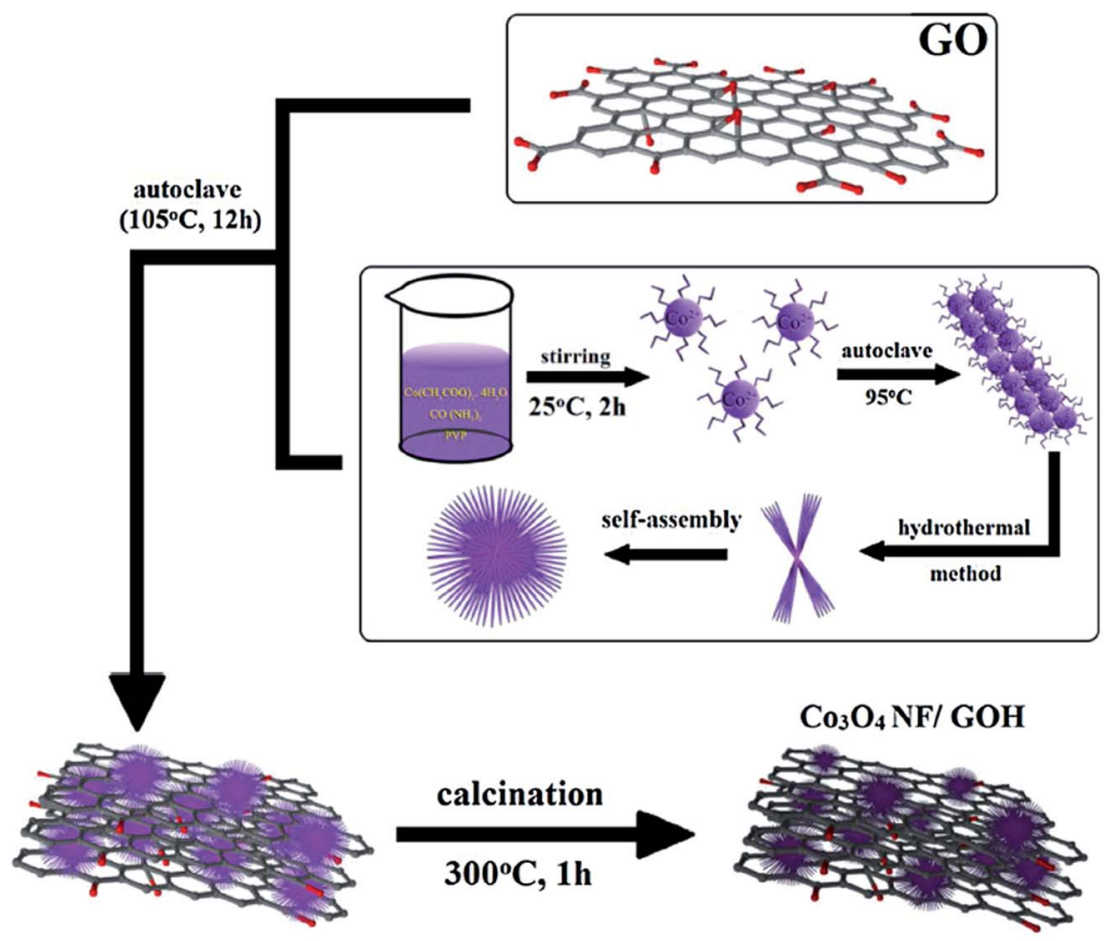

Fig. 13 Schematic representation of the $\mathrm{CO}_{3} \mathrm{O}_{4} \mathrm{NF} / \mathrm{GOH}$ fabrication. ${ }^{88}$

GOH. It is noteworthy that all of the GOH samples were freeze dried at $-37{ }^{\circ} \mathrm{C}$ for 2 days to remove the water without destroying the $3 \mathrm{D}$ networks. Then, the composites were calcined at $300{ }^{\circ} \mathrm{C}$ for $1 \mathrm{~h}$ in an air atmosphere to obtain the $\mathrm{Co}_{3} \mathrm{O}_{4} \mathrm{NF} / \mathrm{GOH}$ hybrid structure. SEM and TEM revealed the formation of $\mathrm{Co}_{3} \mathrm{O}_{4} \mathrm{NF}$ in $\mathrm{GOH}$ network. In addition, $\mathrm{CV}$ was used to evaluate the glucose sensing ability of hydrogels. Results have shown that the addition of $\mathrm{Co}_{3} \mathrm{O}_{4}$ could increase the sensing ability significantly than the pure GOH. Meanwhile, an excellent glucose sensing has been found toward common interfering species uric acid (UA), dopamine (DA), and ascorbic acid (AA). The research shows that $\mathrm{GOH}$ can provide large surface area, which could disperse the $\mathrm{Co}_{3} \mathrm{O}_{4} \mathrm{NF}$ without agglomeration, as well as large electron sink that facilitates the redox reaction.

Excellent swelling properties of graphene-based hydrogels have been studied in Shang's group. ${ }^{\mathbf{8 9}}$ The preparation of polypyrrole/graphene oxide hydrogel is an effect one-step 
strategy for the static assembly of hydrogels from PPy and GO. The static polymerization was triggered in the presence of GO, leading to the formation of PPy-GO hydrogels. In their research, GO suspension and APS were soaked in deionized water and immediately stirred to obtain a uniform dispersion. The resulting hybrid with addition of pyrrole would be kept in standing for $24 \mathrm{~h}$ at room temperature. Then a 1 week immersing in deionized water was required to obtain the PPy-GO hydrogels without any residual reactants. It is proved that GO nanosheets in the polymer network significantly improved the water absorbencies, and even little amount of GO could help exhibiting the superior water uptake ability. In addition, the hydrogels delivered a better water retention ability than pure GO or PPy materials. Finally, the one-step static assembly method is believed to provide possibilities to combine the extraordinary properties of GO with multifunctional performance of conducting polymer materials, which would hold great potential for more technical application.

As we can see from above researches, the introduction of conducting polymer composite(such as PANi, PPy, and PEDOT) in graphene-based hydrogels has been proved to show strong electrochemical activity, which could be applied in gas sensors with high sensitivity. Graphene and derivatives could show no effect on the toxicity of hydrogels when used in cell experiments, so, biomaterial would be another potential application field. ${ }^{90}$ In addition, the novel method to fabricate a kind of 3D porous nitrogen-doped graphene hydrogels can been used as supercapacitor electrodes in ionic liquid electrolyte, which could maintain the excellent capacitive performance after thousands of cycles. ${ }^{91}$

\section{Conclusion and outlook}

At present, excellent electrochemical activities, wide specific area, and rapid responsiveness towards the stimulation (such as temperature, $\mathrm{pH}$, illumination and etc.) of external circumstances have made the graphene-based hydrogels widely applied to the fields of energy storage, wastewater treatment, biosensor and technology, and biomedicine. Nevertheless, many problems should be solved in the course of the development of graphene-based hydrogels. Good electrochemical performance and adsorption property of pollutions are found in the graphene-based hydrogels such as graphene and graphenemetal oxide composite hydrogels, however, the mechanical properties of the composite hydrogels are not ideal enough due to the physical interactions between graphene sheets. Complicated composition of industrial wastewater makes it challenging to develop a graphene-based hydrogel with high adsorption capacity and broad-spectrum property. It is still a big problem to improve the application of the graphene-based hydrogel in drug sustained release via precisely controlling the action temperature and critical $\mathrm{pH}$ value. Finally, the application of graphene-based hydrogels is not limited to the above-mentioned research areas, and it is possible to introduce novel functional materials into graphene-based hydrogel with enhanced properties in various fields through the existing and newly-developed techniques.

\section{Conflicts of interest}

The authors declare that there is no conflict of interests regarding the publication of this paper.

\section{Acknowledgements}

This work was supported by the Natural Science Foundation of China (No. 21706195, 21376282, 51525903, 21275084, 41476083, 21675092), Science and Technology Program of Guizhou Province (QKHJC2016-1149), Guizhou Provincial Department of Education Foundation (QJHKYZ2016-105), Sail plan of Guangdong, China (No. 2015YT02D025), 863 Program (No. 2015AA034404), National Science Fund for Distinguished Young Scholars (51525903), Marine Science and Technology Projects of Huangdao district (2014-4-1), and National Basic Research Program of China (No. 2014CB643304).

\section{References}

1 G. Giovannetti, P. A. Khomyakov, G. Brocks, V. M. Karpan, J. van den Brink and P. J. Kelly, Phys. Rev. Lett., 2008, 101, 026803.

2 C. Berger, Z. M. Song, T. B. Li, X. B. Li, A. Y. Ogbazghi, R. Feng, Z. T. Dai, A. N. Marchenkov, E. H. Conrad, P. N. First and W. A. de Heer, J. Phys. Chem. B, 2004, 108, 19912-19916.

3 A. K. Geim and K. S. Novoselov, Nat. Mater., 2007, 6, 183-191.

4 X. Huang, X. Y. Qi, F. Boey and H. Zhang, Chem. Soc. Rev., 2012, 41, 666-686.

5 G. Eda and M. Chhowalla, Nano Lett., 2009, 9, 814-818.

6 T. Kuilla, S. Bhadra, D. H. Yao, N. H. Kim, S. Bose and J. H. Lee, Prog. Polym. Sci., 2010, 35, 1350-1375.

7 B. Seger and P. V. Kamat, J. Phys. Chem. C, 2009, 113, 79907995.

8 Y. J. Li, W. Gao, L. J. Ci, C. M. Wang and P. M. Ajayan, Carbon, 2010, 48, 1124-1130.

9 J. Du and H.-M. Cheng, Macromol. Chem. Phys., 2012, 213, 1060-1077.

10 Y. Zhang, L. T. Wang, D. B. Lu, X. Z. Shi, C. M. Wang and X. J. Duan, Electrochim. Acta, 2012, 80, 77-83.

11 T. Yang, M. J. Chen, Q. Q. Kong, X. X. Wang, X. H. Guo, W. H. Li and K. Jiao, Electrochim. Acta, 2015, 182, 1037-1045.

12 T. Yang, Q. Q. Kong, Q. H. Li, X. X. Wang, L. H. Chen and K. Jiao, ACS Appl. Mater. Interfaces, 2014, 6, 11032-11037.

13 Y. J. Kim and B. K. Kim, Colloid Polym. Sci., 2014, 292, 51-58. 14 Y. W. Zhu, S. Murali, W. W. Cai, X. S. Li, J. W. Suk, J. R. Potts and R. S. Ruoff, Adv. Mater., 2010, 22, 3906-3924.

15 M. J. Allen, V. C. Tung and R. B. Kaner, Chem. Rev., 2010, 110, 132-145.

16 H. C. Schniepp, J. L. Li, M. J. McAllister, H. Sai, M. HerreraAlonso, D. H. Adamson, R. K. Prud'homme, R. Car, D. A. Saville and I. A. Aksay, J. Phys. Chem. B, 2006, 110, 8535-8539.

17 E. K. Choi, I. Y. Jeon, S. Y. Bae, H. J. Lee, H. S. Shin, L. M. Dai and J. B. Baek, Chem. Commun., 2010, 46, 6320-6322. 
18 E. K. Choi, I. Y. Jeon, S. J. Oh and J. B. Baek, J. Mater. Chem., 2010, 20, 10936-10942.

19 E. Bekyarova, M. E. Itkis, P. Ramesh, C. Berger, M. Sprinkle, W. A. de Heer and R. C. Haddon, J. Am. Chem. Soc., 2009, 131, 1336-1337.

20 G. I. Titelman, V. Gelman, S. Bron, R. L. Khalfin, Y. Cohen and H. Bianco-Peled, Carbon, 2005, 43, 641-649.

21 S. Y. Bae, I. Y. Jeon, J. Yang, N. Park, H. S. Shin, S. Park, R. S. Ruoff, L. M. Dai and J. B. Baek, ACS Nano, 2011, 5, 4974-4980.

22 W. S. Hummers and R. E. Offeman, J. Am. Chem. Soc., 1958, 80, 1339.

23 K. C. Chang, W. F. Ji, M. C. Lai, Y. R. Hsiao, C. H. Hsu, T. L. Chuang, Y. Wei, J. M. Yeh and W. R. Liu, Polym. Chem., 2014, 5, 1049-1056.

24 O. C. Compton and S. T. Nguyen, Small, 2010, 6, 711-723.

25 S. Sallard, J. Patole, V. Soukharev, A. Heller, N. Mano and N. Sojic, Electrochem. Commun., 2009, 11, 599-602.

26 S. H. Lee, C. K. Lee, S. R. Shin, B. K. Gu, S. I. Kim, T. M. Kang and S. J. Kim, Sens. Actuators, B, 2010, 145, 89-92.

27 Y. X. Xu, K. X. Sheng, C. Li and G. Q. Shi, ACS Nano, 2010, 4, 4324-4330.

28 N. N. Zhang, R. Q. Li, L. Zhang, H. B. Chen, W. C. Wang, Y. Liu, T. Wu, X. D. Wang, W. Wang, Y. Li, Y. Zhao and J. P. Gao, Soft Matter, 2011, 7, 7231-7239.

29 H. Bai, K. X. Sheng, P. F. Zhang, C. Li and G. Q. Shi, J. Mater. Chem., 2011, 21, 18653-18658.

30 L. Chen, X. J. Wang, X. T. Zhang and H. M. Zhang, J. Mater. Chem., 2012, 22, 22090-22096.

31 J. Chen, K. X. Sheng, P. H. Luo, C. Li and G. Q. Shi, Adv. Mater., 2012, 24, 4569-4573.

32 L. J. Pan, G. H. Yu, D. Y. Zhai, H. R. Lee, W. T. Zhao, N. Liu, H. L. Wang, B. C. K. Tee, Y. Shi, Y. Cui and Z. N. Bao, Proc. Natl. Acad. Sci. U. S. A., 2012, 109, 9287-9292.

33 Y. Hou, T. Li, H. Y. Huang, H. Quan, X. Y. Miao and M. H. Yang, Sens. Actuators, B, 2013, 182, 605-609.

34 Y. X. Xu, Z. Y. Lin, X. Q. Huang, Y. Liu, Y. Huang and X. F. Duan, ACS Nano, 2013, 7, 4042-4049.

35 Y. X. Xu, Z. Y. Lin, X. Q. Huang, Y. Wang, Y. Huang and X. F. Duan, Adv. Mater., 2013, 25, 5779-5784.

36 S. Chen, J. J. Duan, Y. H. Tang and S. Z. Qiao, Chem.-Eur. J., 2013, 19, 7118-7124.

37 Z. Y. Zhang, F. Xiao, Y. L. Guo, S. Wang and Y. Q. Liu, ACS Appl. Mater. Interfaces, 2013, 5, 2227-2233.

38 Y. X. Xu, X. Q. Huang, Z. Y. Lin, X. Zhong, Y. Huang and X. F. Duan, Nano Res., 2013, 6, 65-76.

39 Y. Q. Han, M. X. Shen, Y. Wu, J. J. Zhu, B. Ding, H. Tong and X. G. Zhang, Synth. Met., 2013, 172, 21-27.

40 Y. F. Wang, X. W. Yang, L. Qiu and D. Li, Energy Environ. Sci., 2013, 6, 477-481.

41 X. She, P. L. Sun, X. H. Yu, Q. Zhang, Y. G. Wu, L. Li, Y. N. Huang, S. M. Shang and S. X. Jiang, J. Inorg. Organomet. Polym. Mater., 2014, 24, 884-889.

42 A. Bejarano-Jimenez, V. A. Escobar-Barrios, J. M. Kleijn, C. A. Ortiz-Ledon and L. F. Chazaro-Ruiz, J. Appl. Polym. Sci., 2014, 131, 40846.
43 G. P. Hao, F. Hippauf, M. Oschatz, F. M. Wisser, A. Leifert, W. Nickel, N. Mohamed-Noriega, Z. K. Zheng and S. Kaskel, ACS Nano, 2014, 8, 7138-7146.

44 Y. Qiu and K. Park, Adv. Drug Delivery Rev., 2001, 53, 321-339. 45 T. Miyata, T. Uragami and K. Nakamae, Adv. Drug Delivery Rev., 2002, 54, 79-98.

46 J. Pluta and B. Karolewicz, Polim. Med., 2004, 34, 3-19.

47 P. Gupta, K. Vermani and S. Garg, Drug Discovery Today, 2002, 7, 569-579.

48 H. Bai, C. Li, X. Wang and G. Shi, Chem. Commun., 2010, 46, 2376-2378.

49 J. J. Liang, Y. Huang, L. Zhang, Y. Wang, Y. F. Ma, T. Y. Guo and Y. S. Chen, Adv. Funct. Mater., 2009, 19, 2297-2302.

50 C. C. Huang, H. Bai, C. Li and G. Q. Shi, Chem. Commun., 2011, 47, 4962-4964.

51 M. Mahkam, A. A. Rafi, L. Faraji and E. Zakerzadeh, Polym.Plast. Technol. Eng., 2015, 54, 916-922.

52 B. Unnikrishnan, V. Mani and S. M. Chen, Sens. Actuators, B, 2012, 173, 274-280.

53 Y. Wang, P. Zhang, C. F. Liu and C. Z. Huang, RSC Adv., 2013, 3, 9240-9246.

54 S. J. Guo and S. J. Dong, Chem. Soc. Rev., 2011, 40, 2644-2672.

55 Y. Q. Chen, L. B. Chen, H. Bai and L. Li, J. Mater. Chem. A, 2013, 1, 1992-2001.

56 H. C. Gao, Y. M. Sun, J. J. Zhou, R. Xu and H. W. Duan, ACS Appl. Mater. Interfaces, 2013, 5, 425-432.

57 H. P. Cong, X. C. Ren, P. Wang and S. H. Yu, ACS Nano, 2012, 6, 2693-2703.

58 G. Wei, Y. E. Miao, C. Zhang, Z. Yang, Z. Y. Liu, W. W. Tjiu and T. X. Liu, ACS Appl. Mater. Interfaces, 2013, 5, 7584-7591.

59 F. M. Plieva, K. A. Kochetkov, I. Singh, V. S. Parmar, Y. N. Belokon' and V. I. Lozinsky, Biotechnol. Lett., 2000, 22, 551-554.

60 Y. E. Miao, Y. P. Huang, C. Zhang and T. X. Liu, Curr. Org. Chem., 2015, 19, 498-511.

61 N. Ni, D. Duquette and M. J. Dumont, Eur. Polym. J., 2017, 91, 420-428.

62 S. L. Loo, T. T. Lim, W. B. Krantz, A. G. Fane and X. Hu, Desalin. Water Treat., 2015, 53, 1506-1515.

63 P. Podsiadlo, A. K. Kaushik, E. M. Arruda, A. M. Waas, B. S. Shim, J. D. Xu, H. Nandivada, B. G. Pumplin, J. Lahann, A. Ramamoorthy and N. A. Kotov, Science, 2007, 318, 80-83.

64 Y. Zhou, Q. L. Bao, L. A. L. Tang, Y. L. Zhong and K. P. Loh, Chem. Mater., 2009, 21, 2950-2956.

65 J. C. Fan, Z. X. Shi, M. Lian, H. Li and J. Yin, J. Mater. Chem. A, 2013, 1, 7433-7443.

66 W. J. Zhang, X. H. Shi, Y. X. Zhang, W. Gu, B. Y. Li and Y. Z. Xian, J. Mater. Chem. A, 2013, 1, 1745-1753.

67 C. J. Madadrang, H. Y. Kim, G. H. Gao, N. Wang, J. Zhu, H. Feng, M. Gorring, M. L. Kasner and S. F. Hou, ACS Appl. Mater. Interfaces, 2012, 4, 1186-1193.

68 X. Tong, H. Cheng and R. Zeng, Mater. Rev., 2014, 28, 99-102. 69 K. Rajeshwar, M. E. Osugi, W. Chanmanee, C. R. Chenthamarakshan, M. V. B. Zanoni, P. Kajitvichyanukul and R. Krishnan-Ayer, J. Photochem. Photobiol., C, 2008, 9, 171192. 
70 J. Du, X. Y. Lai, N. L. Yang, J. Zhai, D. Kisailus, F. B. Su, D. Wang and L. Jiang, ACS Nano, 2011, 5, 590-596.

71 C. Y. Hou, Q. H. Zhang, Y. G. Li and H. Z. Wang, Carbon, 2012, 50, 1959-1965.

72 B. S. Girgis, A. M. Soliman and N. A. Fathy, Microporous Mesoporous Mater., 2011, 142, 518-525.

73 Y. F. Feng, D. D. Dionysiou, Y. H. Wu, H. Zhou, L. H. Xue, S. Y. He and L. Z. Yang, Bioresour. Technol., 2013, 138, 191197.

74 H. S. Shang, Y. J. Lu, F. Zhao, C. Chao, B. Zhang and H. S. Zhang, RSC Adv., 2015, 5, 75728-75734.

75 S. L. Yang, L. Zhang, Q. Y. Yang, Z. H. Zhang, B. Chen, P. Lv, W. Zhu and G. Z. Wang, J. Mater. Chem. A, 2015, 3, 7950-7958.

76 T. Ni, L. Xu, Y. Sun, W. Yao, T. Dai and Y. Lu, ACS Sustainable Chem. Eng., 2015, 3, 862-870.

77 S. Peng, X. Han, L. Li, Z. Zhu, F. Cheng, M. Srinivansan, S. Adams and S. Ramakrishna, Small, 2016, 12, 1359-1368.

78 B. De, T. Kuila, N. H. Kim and J. H. Lee, Carbon, 2017, 122, 247-257.

79 J. Li, G. Zhang, C. Fu, L. Deng, R. Sun and C.-P. Wong, J. Power Sources, 2017, 345, 146-155.

80 L. Wen, K. Li, J. Liu, Y. Huang, F. Bu, B. Zhao and Y. Xu, RSC Adv., 2017, 7, 7688-7693.
81 Y. F. Xu, Z. B. Liu, X. L. Zhang, Y. Wang, J. G. Tian, Y. Huang, Y. F. Ma, X. Y. Zhang and Y. S. Chen, Adv. Mater., 2009, 21, 1275-1279.

82 L. Zhang, Z. P. Wang, C. Xu, Y. Li, J. P. Gao, W. Wang and Y. Liu, J. Mater. Chem., 2011, 21, 10399-10406.

83 M. J. McAllister, J. L. Li, D. H. Adamson, H. C. Schniepp, A. A. Abdala, J. Liu, M. Herrera-Alonso, D. L. Milius, R. Car, R. K. Prud'homme and I. A. Aksay, Chem. Mater., 2007, 19, 4396-4404.

84 B. Das, K. E. Prasad, U. Ramamurty and C. N. R. Rao, Nanotechnology, 2009, 20, 125705.

85 D. Liu, C. P. Fu, N. S. Zhang, H. H. Zhou and Y. F. Kuang, Electrochim. Acta, 2016, 213, 291-297.

86 B. Tan, H. M. Zhao, L. Du, X. R. Gan and X. Quan, Biosens. Bioelectron., 2016, 83, 267-273.

87 Z. Y. Xiong, X. W. Yun, B. Tang and X. G. Wang, Carbon, 2016, 107, 548-556.

88 L. T. Hoa, J. S. Chung and S. H. Hur, Sens. Actuators, B, 2016, 223, 76-82.

89 J. Ji, X. Yu, P. Cheng, Q. Zhang, F. Du, L. Li and S. Shang, J. Macromol. Sci., Part B: Phys., 2015, 54, 1122-1131.

90 Y. F. Huang, M. Q. Zhang and W. H. Ruan, J. Mater. Chem. A, 2014, 2, 10508-10515.

91 Y. H. Chen, Y. L. Wang, X. T. Shi, M. Jin, W. H. Cheng, L. Ren and Y. J. Wang, Carbon, 2017, 111, 38-47. 